\title{
Formação e práticas docentes na educação de jovens e adultos: fragilidades e avanços
}

Teacher training and practices in youth and adult education: weaknesses and advances Formación y prácticas docentes en educación de jóvenes y adultos: debilidades y avances

Recebido: 20/04/2020 | Revisado: 29/04/2020 | Aceito: 02/05/2020 | Publicado: 06/05/2020

Lenir Keller

ORCID: https://orcid.org/00000001-7414-526X

Universidade Franciscana, Brasil

E-mail: lenirkeller@yahoo.com.br

Elsbeth Léia Spode Becker

ORCID: https://orcid.org/0000-0002-9867-1835

Universidade Franciscana, Brasil

E-mail: elsbeth.geo@gmail.com

\section{Resumo}

Neste estudo, o objetivo é refletir sobre a formação inicial e continuada de professores, os saberes e as práticas docentes, com o recorte na Educação de Jovens e Adultos (EJA). A metodologia é qualitativa embasada na pesquisa bibliográfica e documental. O texto discorre sobre as concepções de formação de professores, de saberes e práticas docentes que, de certa forma, dialogam com a modalidade. Além disso, resgata fatos relevantes para compor um breve histórico e amparos legais sobre a formação inicial e continuada de professores pensada para a referida modalidade, para então vislumbrar as fragilidades e os avanços nos contextos nacional e local. Pôde-se inferir que a formação inicial dos docentes, na modalidade EJA, encontra-se em contração, sendo apenas oferecida na forma de uma disciplina nas licenciaturas da Pedagogia. Além disso, a EJA é marcada por especificidades e, por isso, os processos de formação continuada constituem os espaços possíveis para a reflexão docente e a inovação nas práticas para qualificar e dar significado o ensino destinado aos jovens e adultos.

Palavras-chave: Formação Inicial e Continuada; Reflexão; Práticas Docentes.

\footnotetext{
Abstract

In this study, the objective is to reflect on the initial and continuing education of teachers, the knowledge and teaching practices, with a focus on Youth and Adult Education (EJA). The
} 
methodology is qualitative based on bibliographic and documentary research. The text discusses the conceptions of teacher training, knowledge and teaching practices that, in a way, dialogue with the modality. In addition, it retrieves relevant facts to compose a brief history and legal support about the initial and continuing teacher training designed for the referred modality, so that we can glimpse the weaknesses and advances in the national and local contexts. It could be inferred that the initial training of teachers, in the EJA modality, is in contraction, being only offered in the form of a discipline in the degrees of Pedagogy. In addition, EJA is marked by specificities and, therefore, the continuing education processes constitute the possible spaces for teacher reflection and innovation in practices to qualify and give meaning to teaching for young people and adults.

Keywords: Initial and Continuing Education; Reflection; Teaching Practices; Specificities.

\section{Resumen}

En este estudio, el objetivo es reflexionar sobre la educación inicial y continua de los docentes, el conocimiento y las prácticas de enseñanza, con un enfoque en la Educación de Jóvenes y Adultos (EJA). La metodología es cualitativa basada en la investigación bibliográfica y documental. El texto discute las concepciones de la formación del profesorado, el conocimiento y las prácticas de enseñanza que, en cierto modo, dialogan con la modalidad. Además, recupera datos relevantes para componer una breve historia y apoyo legal sobre la formación inicial y continua de maestros diseñada para la modalidad referida, de modo que podamos vislumbrar las debilidades y avances en los contextos nacionales y locales. Se puede inferir que la formación inicial de los docentes, en la modalidad EJA, está en contracción, ofreciéndose solo en forma de disciplina en los grados de Pedagogía. Además, EJA está marcado por especificidades y, por lo tanto, los procesos de educación continua constituyen los posibles espacios para la reflexión e innovación docente en las prácticas para calificar y dar sentido a la enseñanza para jóvenes y adultos.

Palabras clave: Educación inicial y continua; Reflexión; Prácticas de enseñanza; Especificidades.

\section{Introdução}

O professor é o profissional da educação. Na sociedade contemporânea, essa não é uma tarefa fácil, visto que existem muitos fatores que influenciam o exercício da profissão docente, 
desde sua formação até a constituição profissional, sendo que a sua prática profissional moldase nos parâmetros que regem a educação no país.

A docência é uma "profissão do conhecimento", uma vez que o conhecimento e o saber legitimam a profissão. Segundo Marcelo (2009, p. 8), o trabalho docente é baseado no “compromisso em transformar esse conhecimento em aprendizagens relevantes para os alunos". Nessa perspectiva, o professor é um profissional que trabalha com o conhecimento e, para tanto, necessita ter compromisso com a aprendizagem discente.

Nos dias de hoje, ser professor é entender que não só o conhecimento como também os alunos transformam-se muito rapidamente, mais do que em décadas passadas. Para continuar contribuindo adequadamente com o direito discente de aprender, faz-se necessário que os professores continuem estudando, aprendendo e se aprimorando. Portanto, a prática profissional docente não é apenas a de ensinar os alunos, de fazê-los aprender, mas também é necessário o esforço do professor, pois ele deve continuar aprendendo para poder ensinar. Ao abordar a intencionalidade do ensino como especificidade da docência, Tozetto $(2015$, p. 13) enfatiza que o professor necessita desenvolver competências de um intelectual crítico, pois é indispensável "uma ação docente que contemple o ato de educar em sua amplitude e complexidade.

O profissional crítico faz escolhas subsidiado no conhecimento científico, constrói seu conhecimento considerando a diversidade social, cultural, econômica, humana". Logo, o ato de ensinar é complexo e para se constituir um profissional docente crítico, é necessária uma formação inicial e continuada. Por esse motivo, os questionamentos sobre a formação docente, tanto a inicial quanto a continuada, têm sido foco de estudos, pesquisas e debates no cenário educacional brasileiro. As discussões abrangem a qualidade da formação inicial face às mudanças e aos desafios da sociedade atual cada vez mais complexa, fluída e instável, a necessidade e a pertinência da formação continuada se apresenta intrinsecamente ligada às práticas e aos saberes docentes, como uma possível mão dupla para o diálogo entre a teoria e a prática.

Diante da institucionalização da modalidade Educação para Jovens e Adultos (EJA), viabilizada pelos marcos legais, Constituição Federal de 1988 e LDBEN № 9394/96 (BRASIL, 1996), bem como a sua consequente implantação a partir de 2001 no país, os profissionais da Educação Básica e, inclusive os que já atuavam no Ensino Supletivo ${ }^{1}$, seriam as alternativas

\footnotetext{
${ }^{1}$ O Ensino Supletivo foi implantado em 1971 no país, com a finalidade de suprir a escolarização regular para os adolescentes e adultos que não concluíram seus estudos na idade considerada regular (BRASIL, 1971).
} 
para a docência, no entanto, necessitariam de formação continuada para atendimento à nova modalidade de ensino.

A EJA é uma das sete modalidades educacionais definidas pelo Ministério da Educação, sendo especificamente voltada para o público que não concluiu a Educação Básica (Ensino Fundamental e Médio) no período regular. Assim, o objetivo aqui é incentivar as pessoas que pararam os estudos a voltarem para o universo acadêmico, contribuindo para a qualificação profissional e pessoal em sociedade.

É importante considerar que grande maioria dos professores que lecionam na EJA não tem formação inicial para atuar na modalidade. Ao considerar esse aspecto, a legislação determina que as mantenedoras devam ofertar cursos de formação continuada aos professores dessa modalidade. Portanto, a formação recebida depende das iniciativas das mantenedoras ou iniciativas individuais dos professores que decidem participar de cursos de pós-graduação, os quais atualmente já estão disponíveis. Assim, [...] "o que se verifica no país é a ocorrência da EJA pelas mãos, principalmente, de professores do próprio sistema 'regular' de ensino" (Pedroso \& Soares, 2016, p. 257).

Nesse sentido e considerando o contexto atual da EJA, a proposta deste texto é refletir sobre a formação inicial e continuada, os saberes e as práticas docentes, com o recorte na EJA, para então vislumbrar as fragilidades e os avanços nos contextos nacional e local. Para tal propósito, a pesquisa documental foi adotada como procedimento para a compreensão e a produção de conhecimento por meio do levantamento de leis, pareceres e resoluções sobre a formação inicial e continuada dos professores na modalidade EJA. Para trazer as referências teóricas, embasar as discussões e aprofundar o debate sobre o tema, lançou-se mão da pesquisa bibliográfica, pois sua principal vantagem “[...] reside no fato de permitir ao investigador a cobertura de uma gama de fenômenos muito mais ampla do que aquela que poderia pesquisar diretamente" (Gil, 2017, p. 50), buscando o aporte teórico em Zeichner (1993, 2008), Garcia (1999), Freire (2000), Tardif (2010), Di Pierro (2005, 2011), Pedroso e Soares (2016).

O texto do artigo discorre sobre as concepções de formação de professores, de saberes e práticas docentes que, de certa forma, dialoguem com a modalidade. Além disso, resgata fatos relevantes para compor um breve histórico e amparos legais sobre a formação inicial e continuada pensada para a modalidade, para então vislumbrar as fragilidades e os avanços nos contextos nacional e local. 


\section{Metodologia}

A abordagem deste estudo é qualitativa, uma vez que são consideradas as análises conjunturais e os dados sobre a implementação da gestão democrática no país. Esse tipo de pesquisa, de acordo com Creswell (2007), é fundamentalmente interpretativa, já que o pesquisador interpreta os dados, que podem ser a descrição de uma pessoa ou de um cenário. Ao interpretá-los, ele pode chegar a conclusões sobre o seu significado, pessoal e teoricamente, comunicando o que foi aprendido, ao mesmo tempo em que provoca questionamentos.

Desse modo, neste estudo, apoiado na abordagem qualitativa, os procedimentos técnicos adotados envolvem a pesquisa bibliográfica e a pesquisa documental, especialmente, as leis que amparam a EJA.

A pesquisa bibliográfica tem, como base, materiais já elaborados, constituídos, principalmente, de livros e de artigos científicos. Ela visa colocar o pesquisador em contato com o que já se produziu e se registrou a respeito do tema de pesquisa, permitindo, assim, o aprofundamento teórico necessário à pesquisa (GIL, 2017). O referencial teórico desse estudo está fundamentado em autores que apresentam reflexões acerca da formação inicial e continuada, os saberes e as práticas docentes, com o recorte na EJA, buscando o aporte teórico em Zeichner (1993, 2008), Garcia (1999), Freire (2000), Tardif (2010), Di Pierro (2005, 2011), Pedroso e Soares (2016). Autores que retomam a ideia de refletir para a prática docente contextualizada na vivência do aluno.

\section{Reflexões sobre a Formação, Saberes e Práticas Docentes}

Partindo do entendimento de que a formação de professores é um processo contínuo “[...] que vai se constituindo ao longo dos percursos de histórias de vida pessoal e profissional [...]" (Moura, 2009, p. 50), as iniciativas de formação inicial e continuada adquirem uma dimensão determinante para efetivação da modalidade EJA no contexto de especificidades em que está inserida.

Dentre as concepções de formação de professores, Zeichner (1993) propõe que os processos de formação envolvam a reflexão sobre a própria experiência no conjunto de professores. A "bandeira da reflexão" (Zeichner, 1993) surgiu como contraponto às formações que consideravam os professores como técnicos, sem participação nas formulações das finalidades e ações do trabalho que iriam desenvolver. A "bandeira da reflexão" também denota impactos estruturantes nos programas de formação, pois significa a valorização das 
experiências dos professores, o reconhecimento de que eles são também produtores de conhecimento e não meros consumidores, que devem desempenhar um papel ativo nas formulações das finalidades do seu trabalho e que o processo de aprender a ensinar se prolonga por toda a carreira docente.

Nesse contexto, a concepção de reflexão está apoiada na dicotomia ação e pensamento, teoria e prática, mas não como elementos contrastantes ou antagônicos e sim, complementares, pois " [...] a diferença entre teoria e prática é, antes de mais nada, um desencontro entre a teoria do observador e a do professor, e não um fosso entre a teoria a prática" (Zeichner, 1993, p. 21). Dessas considerações, advém o conceito de prática reflexiva “[...] como a vinda à superfície das teorias práticas do professor, para análise crítica e discussão" (Zeichner, 1993, p. 21).

Retomando a reflexão como conceito estruturante na formação docente e vinculada às lutas por justiça social, Zeichner (2008, p. 546) afirma que "[...] as ações educativas dos professores, nas escolas, obviamente, não podem resolver os problemas da sociedade por elas mesmas, por outro lado, elas podem contribuir para a construção de sociedades mais justas e mais decentes", ultrapassando a abordagem tecnicista para dar lugar à formação de profissionais que compreendam os contextos sócio-políticos, estabelecendo-se o ensino como uma atividade reflexivo-crítica.

García (1999) adota o conceito do desenvolvimento profissional dos professores, que trata a formação de professores como processo marcado pela evolução, continuidade e inserção no contexto escolar, pois é na prática que se vive a realidade de uma escola e todas as implicações da docência, sugerindo que

A separação entre conhecimento prático e teórico não pode manter-se por mais tempo, sobretudo se é o próprio professor em formação que tem de fazer a integração entre ambos tipos conhecimento. É necessário que, juntamente com o conhecimento pedagógico, as instituições de formação de professores potenciem o que temos vindo a chamar de conhecimento didático do conteúdo, um conhecimento didático do conteúdo a ensinar, que se adquire na medida em que se compreende e aplica. (Garcia, 1999, p.97)

Tardif (2010) se posiciona sobre a necessidade de articulação entre os conhecimentos produzidos e a práticas docentes, seguindo a perspectiva do reconhecimento e a valoração da prática, dos saberes dos professores e de uma postura reflexiva para a formação docente.

Ensinar é mobilizar uma ampla variedade de saberes, reutilizando-os no trabalho para adaptá-los e transformá-los pelo e para o trabalho. A experiência para o trabalho, portanto, é apenas um espaço onde o professor aplica saberes, sendo ela mesma saber do trabalho sobre saberes, em suma, reflexibilidade, retomada, reprodução, reiteração 
daquilo que se sabe naquilo que se sabe fazer, a fim de produzir sua prática profissional (Tardif, 2010, p.21).

Sobre a ampla variedade de saberes, os quais são integrados na prática por meio de diferentes relações, Tardif (2010, p. 36) anuncia que "pode-se definir o saber docente como um saber plural, formado pelo amálgama, mais ou menos coerente, de saberes oriundos da formação profissional e de saberes disciplinares, curriculares e experienciais". Os saberes profissionais abarcam um conjunto de conhecimentos oriundos das ciências e da erudição, tratados durante o processo de formação inicial e continuada. Incluem-se também os conhecimentos pedagógicos relacionados ao ensino. Já os saberes disciplinares são aqueles que correspondem “ $[\ldots]$ aos diversos campos do conhecimento, aos saberes de que dispõem a nossa sociedade, tais como se encontram hoje integrados nas universidades, sob a forma de disciplinas, no interior de faculdades e de cursos distintos" (Tardif, 2010, p. 38). Quanto aos saberes curriculares, estes “[...] apresentam-se concretamente sob a forma de programas escolares (objetivos, conteúdos, métodos), que os professores devem aprender a aplicar" (Tardif, 2010, p. 38). Ainda, os saberes experienciais resultam do próprio exercício da atividade profissional dos professores. Esses saberes são produzidos pelos docentes por meio da vivência de situações específicas relacionadas ao espaço da escola e às relações estabelecidas com os alunos e colegas de profissão, ou seja, esses saberes "incorporam-se à experiência individual e coletiva sob a forma de habitus e de habilidades, de saber-fazer e de saber-ser" (Tardif, 2010, p. 39). Dessa forma, na prática docente, o professor ressignifica os saberes construídos na sua trajetória profissional, seja nos cursos de formação inicial, seja nos encontros de formação continuada, num movimento reflexivo sobre teoria e prática, num dado espaço, tempo e coletivo profissional e social.

Diante do exposto, corporifica-se a convicção de que a experiência docente "[...] é o território próprio da formação de professores, pois só ela atua com forças vivas e inquietantes sobre os sujeitos, forças estas que não se encontram plasmadas nos espaços escolares, tampouco nas universidades" (Feltrin, Baptista \& Becker, 2017, p. 2)

Ao se falar em formação de professores que atuam no ensino para jovens e adultos, não há como não se reportar a Freire (2000), que discute quais são os saberes necessários às práticas docentes, pensando também nas necessidades de aprendizagem dos educandos, pois "não há docência, sem discência” (Freire, 2000, p.12). Assim, inaugura-se uma nova relação de ensinar e aprender, como um processo único e indissociável de troca de conhecimentos, no qual quem 
ensina aprende e quem aprende ensina, assentando professores e educandos como sujeitos de suas aprendizagens.

Para o autor, a formação de professores precisa considerar a prática educativa numa perspectiva reflexiva e crítica, que envolve "o movimento dinâmico, dialético, entre o fazer e o pensar sobre o fazer" (Freire, 2000, p.17), enfatizando que

[...] o momento fundamental é o da reflexão crítica sobre a prática. É pensando criticamente a prática de ou de ontem que se pode melhorar a próxima prática. O próprio discurso teórico, necessário à reflexão crítica, tem de ser de tal modo concreto que quase se confunda com a prática $\mathrm{O}$ seu 'distanciamento' epistemológico da prática enquanto objeto de sua análise, deve dela 'aproximá-lo' ao máximo. Quanto melhor faça esta operação tanto mais inteligência ganha da prática em análise e maior comunicabilidade exerce em torno da superação da ingenuidade pela rigorosidade (Freire, 2000, p.18).

Nessa lógica, a formação de professores promove a apropriação e o compartilhamento de saberes, envolvendo o cotidiano da escola em direção à autonomia, ratificando o legado de Paulo Freire como uma contribuição fundamental para o desenvolvimento de práticas críticoreflexivas, amparadas na vivência. Ou seja, deve haver uma aproximação entre a epistemologia e os cenários da vida cotidiana.

De acordo com Nóvoa, "ser professor obriga a opções constantes, que cruzam a nossa maneira de ser com maneira de ensinar, e que desvendam na nossa maneira de ensinar a nossa maneira de ser" (Nóvoa, 2013, p. 10). Nesse âmbito, o caminho para a percepção e compreensão desta complexidade se apresenta como um desafio e requer que a formação de professor nunca esteja terminada, mas em constante elaboração, desde a formação inicial e fortalecida na formação continuada, amparada nos marcos legais.

\section{A formação Inicial e Continuada de Professores para a EJA: Breve Histórico e Amparos Legais}

O ensino para jovens e adultos atravessou a história marcado por improvisos. Os primeiros registros datam do Brasil Colônia, com a catequização dos índios e o ensino de ofícios a esses e aos escravizados, sob responsabilidade dos padres jesuítas. Ademais, os adultos, quando tinham acesso ao ensino, os seus mestres eram os professores que atuavam na educação primária, sendo leigos ou voluntários.

A necessidade de formação específica para os professores que desempenham atividades docentes para jovens e adultos veio a ser abordada somente na Lei da Reforma do Ensino de $1^{\circ}$ e $2^{\circ}$ Graus, $n^{\circ} 5692 / 71$, que criou o ensino supletivo destinado para jovens e adultos. O Art. 
32 determinava que "o pessoal docente do ensino supletivo terá preparo adequado às características especiais desse tipo de ensino, de acordo com as normas estabelecidas pelos Conselhos de Educação" (Brasil, 1971), inserindo-se na perspectiva de qualificação docente para atendimento das especificidades do ensino. Entretanto,

[...] essas iniciativas não modificaram as propostas e práticas para a área, principalmente no que se refere a uma política deformação de professores. A oferta sistemática de escolarização para adultos do Ensino Supletivo continuava sendo desenvolvida como uma prática semelhante às desenvolvidas com crianças de forma que não somente os procedimentos e recursos metodológicos eram transplantados, mas toda a prática (Moura, 2009, p.51).

Mas no final dos anos 80, a mudança do cenário político levou à promulgação da Constituição Cidadã (1988), à aprovação de uma nova lei para a educação nacional, a LDBEN n ${ }^{\circ}$ 9394/96, que criou a modalidade EJA. A formação para os profissionais da educação teve seu espaço garantido no Art. 61, com a finalidade de atender aos objetivos dos diferentes níveis e modalidades de ensino e às características de cada fase do desenvolvimento do educando (Brasil, 1996), amparando-se nos princípios da associação entre teoria e prática e no aproveitamento da formação e experiências anteriores. A oferta de programas de educação continuada para os profissionais de educação dos diversos níveis consta no Art. 63, cabendo aos institutos superiores de educação a promoção e organização dessa formação.

Ao determinar as Diretrizes Curriculares Nacionais para a Educação de Jovens e Adultos, o Parecer CNE/CEB N 11/2000 manifesta-se sobre a formação dos professores para a modalidade. De acordo com esse parecer, “[...] pode-se dizer que o preparo de um docente voltado para a EJA deve incluir, além das exigências formativas para todo e qualquer professor, aquelas relativas à complexidade diferencial desta modalidade de ensino" (Brasil, 2000a, p. 52).

Para atender a essa demanda, as instituições formadoras devem ser chamadas a oferecer habilitação para a docência na modalidade em seus processos seletivos, desde a inclusão nos cursos normais às licenciaturas. É sugerido que a formação continuada seja promovida por meio de cursos de pós-graduação e, para tal, é proposta a articulação entre as mantenedoras e as instituições formadoras, com vistas à viabilização de programas de formação condizentes com a caracterização e os diferenciais da EJA.

Seguindo a mesma linha de atendimento às diferenças da modalidade e à necessidade de formação específica para os professores, a Resolução CNE/CEB n ${ }^{\circ} 1 / 2000$, que estabelece as Diretrizes Curriculares Nacionais para a Educação de Jovens, determina: 
Art. 17 - A formação inicial e continuada de profissionais para a Educação de Jovens e Adultos terá como referência as diretrizes curriculares nacionais para o ensino fundamental e para o ensino médio e as diretrizes curriculares nacionais para a formação de professores, apoiada em: I - ambiente institucional com organização adequada à proposta pedagógica; II - investigação dos problemas desta modalidade de educação, buscando oferecer soluções teoricamente fundamentadas e socialmente contextuadas; III - desenvolvimento de práticas educativas que correlacionem teoria e prática; IV utilização de métodos e técnicas que contemplem códigos e linguagens apropriados às situações específicas de aprendizagem. (Brasil, 2000b)

No ano seguinte (2001), o Conselho Nacional de Educação (CNE) emitiu o Parecer CNE/CP 009/2001, que trata sobre os Curriculares Nacionais para a Formação de Professores da Educação Básica, em nível superior, curso de licenciatura, de graduação plena. No teor do documento, são exaradas questões a serem enfrentadas na formação professores. No campo curricular, há apontamentos sobre a desconsideração das especificidades próprias dos níveis e/ou modalidades de ensino em que são atendidos os alunos da educação básica, incluindo a EJA:

Inúmeras experiências apontam a necessidade de pensar a especificidade desses alunos e de superar a prática de trabalhar com eles da mesma forma que se trabalha com os alunos do ensino fundamental ou médio regular. [...] Os cursos de formação devem oferecer uma ênfase diferencial aos professores que pretendem se dedicar a essa modalidade de ensino, mudando a visão tradicional desse professor de "voluntário" para um profissional com qualificação específica (Brasil, 2001, p.26).

Nos anos subsequentes, a formação inicial e continuada para a EJA foi mencionada em pareceres (Parecer CNE/CP nº. 5/2005, Parecer CNE/CEB nº. 6/2010a) e resoluções emitidas pelo Conselho Nacional de Educação (Resolução (CNE/CP n ${ }^{\circ}$. 1/2002, Resolução CNE/CP nº. 1/2006, Resolução CNE/CP n²/2015), ora sendo contemplada de forma generalizada, ora sendo diluída nas demais orientações.

Já a Resolução CNE/CEB no. 3/2010, que instituiu as Diretrizes Operacionais para a EJA (BRASIL, 2010b), propôs políticas e ações específicas para professores de Educação Básica de Jovens e Adultos por meio do Programa Universidade Aberta do Brasil (UAB), na modalidade Educação a Distância:

Art. 10. O Sistema Nacional Público de Formação de Professores deverá estabelecer políticas e ações específicas para a formação inicial e continuada de professores de Educação Básica de jovens e adultos, bem como para professores do ensino regular que atuam com adolescentes, cujas idades extrapolam a relação idade-série, desenvolvidas 
em estreita relação com o Programa Universidade Aberta do Brasil (UAB), com as Universidades Públicas e com os sistemas de ensino (Brasil, 2010b).

Ainda em 2010, a Resolução n 4/2010, que definiu as Diretrizes Curriculares Nacionais para a Educação Básica (Brasil, 2010c), resolveu que os cursos de EJA devem ser ministrados preferencialmente tendo a Educação Profissional articulada com a Educação Básica, e pautarse pela flexibilidade, tanto de currículo quanto de tempo e espaço, e que seja "[...] realizada, sistematicamente, a formação continuada, destinada, especificamente, aos educadores de jovens e adultos" (Brasil, Art. 28, 2010c).

O Plano Nacional de Educação (PNE 2014-2024), de forma mais genérica, ou seja, direcionada a todos os profissionais da educação, na Meta 16, objetiva garantir a formação continuada a todos os professores da Educação Básica conforme a sua área de atuação, levando em conta as necessidades, demandas e contextualizações dos sistemas de ensino (Brasil, 2014).

Pedroso e Soares (2016), ao retomarem os principais amparos legais, afirmam que legislação para a EJA apresentou avanços nos últimos anos:

Aos poucos, a própria legislação incorporou a necessidade de uma formação diferenciada desse educador. [...] a nova LDB, Lei 9394/96, enfatiza a necessidade de uma preparação adequada ao educador de jovens e adultos. As Diretrizes Curriculares Nacionais (DCN) para a EJA, regulamentadas por meio do Parecer 11/2000 e aprovadas na Câmara de Educação Básica (CEB) do Conselho Nacional de Educação (CNE), também propõem um importante movimento no que se refere à formação do educador desse campo de ação educativa, ao destacar as especificidades exigidas desse profissional (Pedroso \& Soares, 2016, p. 255).

Os avanços alcançados no plano legal requerem desdobramentos para a sua viabilização como a definição de programas de formação, acompanhamento, financiamento e apoio aos sistemas de ensino, muito além e muito mais sólidas do que as ações localizadas, dispersas e descontínuas que têm marcado as iniciativas para a formação de professores para a modalidade. Portanto, um ponto importante a realçar é que não é possível vislumbrar melhoria na EJA sem valorizar o professor em seus espaços de atuação.

\section{A Formação Inicial e Continuada de Professores para EJA nos Contextos Nacionais e Locais: Fragilidades e Avanços}

A EJA é uma modalidade não consolidada nos sistemas de ensino (Di Pierro, 2011) e ainda não está claro o suficiente o perfil do educador, para então balizar os processos formação. 
Esse obstáculo reside no fato de que também não há definição do perfil do aluno e da própria EJA. De acordo com Arroyo, "em outros termos, podemos dizer que se não temos políticas fechadas de formação de educadores para EJA é porque ainda não temos também políticas muito definidas para a própria educação de jovens e adultos” (Arroyo, 2006, p.18).

Nesta mesma perspectiva de indefinições, Pedroso e Soares (2016) afirmam que:

Outro aspecto importante a ser destacado em relação à formação de educadores de jovens e adultos é a inexistência de parâmetros oficiais que possam delinear o perfil desse profissional. Isso pode ser associado ao fato de não termos ainda uma definição muito clara da própria EJA, pois se trata de uma área em processo de amadurecimento e, portanto, com muitas interrogações. (Pedroso \& Soares, 2016, p. 257).

Ao discutir sobre as dificuldades encontradas na formação inicial e continuada de professores para a modalidade, Machado (2008) retoma as proposições dos encontros e fóruns da EJA, que apontam para a necessidade de criação de uma rede de formação e pesquisa, garantia de investimentos para formação inicial e continuada e que o professor da modalidade seja pesquisador de sua práxis pedagógica, sendo este o princípio orientador dos processos de formação.

Referindo-se à formação de professor para jovens e adultos, Moura (2009, p. 48) considera que “[...] é necessário uma avaliação e uma revisão da prática educativa e da formação inicial e continuada desses educadores, principalmente se considerarmos as especificidades e as particularidades dos sujeitos-alunos-trabalhadores".

Dessa forma, a compreensão da própria EJA, sem o reconhecimento das suas especificidades, tende a perpetuar as práticas de "um professor generalista que poderá dar aula no diurno, a crianças e adolescentes, e no noturno, a jovens e adultos” (Arroyo, 2006, p.21), uma vez que geralmente esses docentes acumulam a jornada de trabalho, atuando no ensino regular diurno, com crianças, pré-adolescentes e/ou adolescentes, e à noite, com a EJA. Di Pierro acrescenta que

A maioria desses/as professores/as transpõe o modelo escolar e tentam adaptar os currículos e as metodologias a este público específico, ou reproduzem com os jovens e adultos as mesmas dinâmicas de ensino aprendizagem que estabelecem com crianças e adolescentes (Di Pierro, 2011, p.168).

Por conseguinte, Arroyo (2006) discorre sobre as formações para professores da EJA partirem de bases teóricas sólidas para dar conta dos processos educativos para jovens e 
adultos, inclusive propõe a criação de um nova Pedagogia, a "Pedagogia da vida adulta, da juventude”, a qual teorizaria “[...] sobre os processos de formação de quem já pensa, já tem voz e questionamentos, de alguém que está sendo construído em múltiplos espaços", com a finalidade de "vincular a construção dessa teoria pedagógica com as grandes matrizes formadoras que tiveram por referência a vida adulta. Quais seriam elas? Educação e trabalho, movimentos sociais, cultura" (Arroyo, 2006, p. 26-27).

Pedroso e Soares (2016) argumentam que as bases teóricas existentes, focadas nas aprendizagens dos períodos da infância e adolescência, não incluem características próprias dos alunos da EJA e, portanto, não dão suporte para a formação dos educadores da modalidade, sugestionando como desafio "a construção, pelos próprios educadores da EJA, de uma proposta pedagógica que privilegie os processos de formação dos jovens e adultos" (Pedroso \& Soares, 2016, p. 259).

De fato, a formação inicial e continuada de professores para a EJA requer “[...] espaços e processos próprios de qualificação" (Di Pierro, 2005, p. 1132), mas, embora com avanços existentes no campo formal, persistem os obstáculos no campo da execução.

As dificuldades de instituição e consolidação de espaços de formação decorrem de múltiplos fatores, como a persistência da visão equivocada que concebe a educação de jovens e adultos como território provisório sempre aberto à improvisação; a precariedade do mercado de trabalho, que não proporciona a construção de carreiras profissionais; e o escasso envolvimento das instituições de ensino superior com um campo educativo de pouco prestígio e baixo grau de formalização (Di Pierro, 2005, p.1132).

Em vista do exposto, a formação inicial e continuada de professores para a EJA configurou-se, e ainda se configura, como um desafio que expressa um descompasso, de forma mais contundente em relação à formação inicial, que ocupa um espaço reduzido e com tendência de encolhimento ainda mais, acompanhando o movimento de redução do número das matrículas de alunos e de escolas com EJA no país. Nesse sentido,

As pesquisas confirmam que a quase totalidade dos/as educadores/as não recebeu formação prévia para o exercício da docência junto aos jovens e adultos. Investigando a formação acadêmica "inicial" de professores/as, Leôncio Soares constatou que entre 2002 e 2005 a proporção das instituições de ensino superior com cursos de Pedagogia que ofereciam a alternativa de habilitação específica para a docência com jovens e adultos oscilou entre $1,6 \%$ e 2,6\%, e concluiu que havia um grande déficit de professores preparados para atuar na modalidade (Soares, 2006; Soares \& Simões, 2004, Di Pierro, 2011, p.168-169) 
Di Pierro (2011) ressalta que não existem estímulos para correção deste quadro de ausência de programas de formação para os professores que pretenderiam atuar (formação inicial) ou atuam na EJA (formação continuada), e que o Estado tem sido omisso na formação acadêmica de educadores para jovens e adultos. Na mesma linha de pensamento, Moura (2009, p. 49) já havia se manifestado de forma bastante acentuada. Segundo essa autora,

Ainda no século XXI, permanece o silêncio e o vazio institucional na formação inicial de professores para a modalidade. Permanece a improvisação de professores e a transposição de professores do Ensino Fundamental de crianças e adolescentes para atuarem na prática pedagógica com jovens, adultos e idosos, tal como se registrava nos primórdios da história da educação.

O não reconhecimento das especificidades da EJA acarreta a "conformação de um círculo vicioso" (Di Pierro, 2011) que se estabelece devido à reduzida institucionalização da modalidade nos sistemas de ensino, que, por sua vez, não infla a demanda para formação específica inicial de professores, o que não torna atrativa a constituição da carreira profissional na EJA, restando como possibilidade da qualificação docente a formação continuada, a qual carece de sistematização e financiamento.

Por outro lado, na contemporaneidade, os pesquisadores e os estudiosos da EJA reconhecem que há "um conjunto de experiências e trajetórias formativas" que podem tornarse "ponto de partida para formulação de programas de formação" (Pedroso \& Soares, 2016, p. 260), resgatando e valorizando os saberes docentes adquiridos nas vivências, durante o exercício na modalidade.

No âmbito da Rede Municipal de Ensino de Santa Maria, há dificuldades no tratamento da evolução das políticas de formação de professores para a EJA pela precariedade de sistematização dos programas e ações desenvolvidas. Há informações sobre o treinamento de professores para atuarem no MOBRAL e também encontros de formação preparatórios para implementação do Ensino Supletivo na primeira metade dos anos 70, inclusive participar destes encontros era a condição para poder atuar no ensino noturno (sic). A partir de 2001, com o funcionamento da EJA, sabe-se (sic) que também foram desenvolvidos processos de formação continuada para os professores e formação de alfabetizadores para atuarem no Programa Brasil Alfabetizado.

Merece destaque o acordo firmado pela Prefeitura Municipal de Santa Maria, o Instituto Paulo Freire e a Editora Líber no ano de 2007, para a promoção da formação continuada dos professores da EJA e também como atividade preparatória para a realização do Fórum Mundial 
de Educação, em 2008, na cidade. O acordo contemplou a publicação e disponibilização para os professores e escolas, as obras da Série Educação de Adultos, com três volumes: 1) Cenários, Perspectivas e Formação de Educadores (Romão \& Gadotti, 2007); 2) Método Paulo Freire: A reinvenção de um legado (Feitosa, 2008); 3) Paulo Freire e a Educação de Adultos: Teorias e Práticas (Romão \& Rodrigues, 2011).

Atualmente, a formação continuada dos professores que atuam na EJA acontece em reuniões pedagógicas das escolas e em encontros regulares durante o ano letivo, envolvendo socialização de experiências realizadas, orientações curriculares, metodologia e avaliação.

Em relação à formação inicial, as instituições de ensino superior locais, como a Universidade Federal de Santa Maria (UFSM) e a Universidade Franciscana (UFN), oferecem a disciplina Educação de Jovens e Adultos como optativa no curso de Pedagogia. Considerando o exposto, as limitações existentes na esfera municipal espelham a realidade de outras experiências.

O cenário onde as ações de formação se desenvolvem reflete o quadro da educação de jovens e adultos observado em várias partes do país: a maior parte dos projetos assessorados funciona em condições adversas, com carência de fontes regulares e suficientes de financiamento, de formação inicial específica para os educadores e de materiais que apoiem seu desenvolvimento, entre outros (Vovio \& Bicas, 2006, p.202).

A modalidade de ensino EJA e sua configuração, pautada em especificidades distintas, como a proposta curricular e metodológica, a valorização da trajetória de vida e as demandas de escolarização dos educandos, a formação dos professores igualmente deve ser concebida tendo em vista esses diferenciais que a compõem. Nesse sentido, Soares (2008, p. 85) reitera que "a formação dos educadores tem se inserido na problemática mais ampla da instituição da EJA como um campo pedagógico específico que, desse modo, requer a profissionalização de seus agentes".

Esse é o enorme desafio que se coloca para os cursos de formação de professores. Não se trata somente de procedimentos ou regulamentações, é necessário trazer para o palco os papéis das universidades que, nesse momento de mudança de comportamento da sociedade pósmoderna, estão em questão: o que sabiam fazer ou achavam que sabiam fazer já não sabem mais. Resta à universidade construir e engendrar, com os sistemas de ensino, com as escolas e com os espaços educadores na sociedade, processos formativos mais integrados e integradores.

Torna-se fundamental incluir distintos movimentos envolvendo conhecimentos básicos para o processo de aprendizagem da profissão. Novos paradigmas estão em construção, 
estando a formação inicial e continuada, chamadas a participar. Da mesma forma, é necessário considerar que o processo de formação de professores é resultado também do compromisso de cada professor com seu próprio desenvolvimento pessoal e profissional. Para Nóvoa (1991), são os professores que atribuem, ou não, sentido ao que fazem e ao que externamente recebem. E isso os torna corresponsáveis pelos processos formativos e pelos desdobramentos dessa formação, na prática dos que escolhem o nome "professor" como sua identidade profissional. Assim, as perspectivas indicam que o empenho para a mudança deve, também, ser dos professores em regência, especialmente na compreensão do universo da formação docente e discente, trazendo contribuições às políticas e normatizações estabelecidas para a EJA.

\section{Conclusão}

O reconhecimento e a valorização da formação inicial e continuada para os professores figuram-se como elementos determinantes para a qualidade de educação e como meio para a profissionalização da docência, e, como visto, encontram amparo na legislação educacional. A trajetória da EJA mostrou avanços nos marcos legais quanto à concepção e constituição, estando a formação inicial e continuada neste contexto. No entanto, a consecução do que está institucionalizado acabou corroendo os avanços obtidos e, desta forma, a viabilidade da oferta de um ensino de qualidade e garantia da educação como um direito humano subjetivo.

A viabilização de formações específicas para os professores de EJA encontra barreiras no financiamento de programas, na organização e na disponibilidade de tempo, tanto o escolar quanto o docente, pois o que se visualiza é o aproveitamento dos professores que já atuam no ensino regular e que se dispõem a atuar na modalidade, agravado pelo fato da carência ou ausência da oferta de formação inicial. Diante disso, as especificidades da modalidade e, consequentemente, dos processos de formação de um profissional que atua ou atuará na EJA acabam diluindo-se em adaptações e arranjos.

Nesse sentido, as discussões sobre a formação de professores são de extrema relevância, dada a complexidade do mundo atual e os constantes tensionamentos estruturais das sociedades modernas, exigindo da educação novas formas de se organizar e se compor, e muito mais ainda para a EJA, que se volta para jovens e adultos, sem trajetórias escolares ou interrompidas, mas que buscam a (re)inserção nos processos educacionais, trazendo para dentro da escola o mundo real, onde os deveres e os direitos têm espaços e medidas diferentes.

Portanto, é preciso avançar nas políticas públicas para a modalidade, contemplando a formação de professores, no que tange aos saberes necessários à sua profissionalização e 
(re)significação da sua prática, que se convertam em propostas pedagógicas diferenciadas para que essas se traduzam em práticas que dialoguem com as necessidades de aprendizagem dos educandos da EJA. Assim, os processos de formação inicial e continuada para professores dessa modalidade, que tomam como base a reflexão e valorizam as experiências dos professores como fonte de conhecimento para a construção dos saberes necessários para a docência, os quais, na prática, são mobilizados, transformados, produzindo novos conhecimentos, coadunam-se com a caracterização da modalidade, suas especificidades e finalidades.

Portanto, ao problematizar os processos de formação inicial e continuada para a EJA, envolvendo questões sobre os contextos nacional e local, as políticas e programas de formação, as iniciativas das mantenedoras, a realidade e vivências docentes, buscou-se a inserção no seu universo complexo, defendendo-se a ideia de que, dada a atual conjuntura, os processos de formação continuada sobressaem-se com espaços possíveis para reflexão, contribuindo para a potencialização da EJA como garantia do direito à educação de qualidade para todos.

\section{Referências}

Arroyo, M. (2006). Formar educadoras e educadores de jovens e adultos. In: Soares, L.(org.) Formação de educadores de jovens e adultos. Belo Horizonte: Autêntica/SECADMEC/UNESCO, p.17-32.

Brasil. (2000). Conselho Nacional de Educação. Parecer CNE/CEB n 11/2000, de 10 de maio de 2000. Institui as Diretrizes Curriculares Nacionais para a Educação de Jovens e Adultos. Diário Oficial da União, Brasília, DF, 9 jun. 2000a, Seção 1, p. 15.

Brasil.(2002). Conselho Nacional de Educação. Parecer CNE/CP $n^{\circ}$ 9/2001, de 18 de janeiro de 2002. Diretrizes Curriculares Nacionais para a Formação de Professores da Educação Básica, em nível superior, curso de licenciatura, de graduação plena. Brasília DF, 2002. Disponível em: http://portal.mec.gov.br/cne/arquivos/pdf/009.pdf. Acesso em: 22 out. 2019.

Brasil. (2005). Conselho Nacional de Educação. Parecer CNE/CP $n^{o}$. 5/2005. Institui Diretrizes Curriculares Nacionais para o Curso de Pedagogia. Brasília: CNE, 13, dez. 
Brasil. (2010). Conselho Nacional de Educação. Parecer CEB $n^{\circ}$ 6, de 7 de abril de 2010.

Reexamina o Parecer CNE/CEB nº. 23/2008 que instituiu as Diretrizes Operacionais para a EJA nos aspectos relativos à duração dos cursos e idade mínima para ingresso; idade mínima e certificação nos exames de EJA e EJA desenvolvida por meio da Educação a Distância. Diário Oficial da União, Brasília, DF, 9 jun. 2010a. Seção 1. p. 20.

Brasil. (2019). Conselho Nacional de Educação. Resolução $C N E / C P n^{o} 1$, de 18 de fevereiro de 2002. Institui Diretrizes Curriculares Nacionais para a formação de professores da Educação Básica, em nível superior, curso de licenciatura, de graduação plena. Brasília, DF. Disponível em: http://portal.mec.gov.br/cne/arquivos/pdf/rcp01_02.pdf. Acesso em: 22 out. 2019.

Brasil. (2000b). Conselho Nacional de Educação. Resolução CNE/CEB n $n^{o} 1 / 2000$, de 5 de julho de 2000. Estabelece as Diretrizes Curriculares Nacionais para a Educação de Jovens e Adultos. Brasília DF. Disponível em:

http://portal.mec.gov.br/cne/arquivos/pdf/CEB012000.pdf. Acesso em: 22 out. 2019.

Brasil. (2006). Conselho Nacional de Educação. Resolução CNE/CP $n^{o}$. 1, de 15 de maio de 2006. Institui Diretrizes Curriculares Nacionais para o Curso de Graduação em Pedagogia, licenciatura. 2006b. Diário Oficial da União, Brasília, 16 mai. Seção 1.

Brasil. (2010b). Conselho Nacional de Educação. Resolução CNE/CEB $n^{o} 3$, de 15 de junho de 2010. Institui Diretrizes Operacionais para a Educação de Jovens e Adultos nos aspectos relativos à duração dos cursos e idade mínima para ingresso nos cursos de EJA; idade mínima e certificação nos exames de EJA; e Educação de Jovens e Adultos desenvolvida por meio da Educação a Distância. Brasília, DF. Disponível em:

http://portal.mec.gov.br/index.php?option=com_docman\&view=download\&alias=5642rceb003-10\&category_slug=junho-2010-pdf\&Itemid=30192. Acesso em: 22 out. 2019.

Brasil. (2010c). Conselho Nacional de Educação. Resolução CNE/CEB no 4/2010, de 13 de julho de 2010. Define Diretrizes Curriculares Nacionais Gerais para a Educação Básica. Brasília DF. Disponível em: http://portal.mec.gov.br/dmdocuments/rceb004_10.pdf. Acesso em: 22 out. 2019. 
Brasil. (1962). Ministério da Educação. Lei de Diretrizes e Bases da Educação Nacional $n^{o}$ 4.024/61, de 20 de dezembro de 1961. Fixa as Diretrizes e Bases da Educação Nacional. Brasília: Ministério da Educação. Disponível em: https://www2.camara.leg.br/legin/fed/lei/1960-1969/lei-4024-20-dezembro-1961-353722publicacaooriginal-1-pl.html. Acesso em: 15 mar. 2019.

Brasil. (1971). Ministério da Educação. Lei da Reforma do Ensino de $1^{o}$ e $2^{o} \mathrm{Graus}, n^{o}$ $5692 / 71$, de 12 de agosto de 1971. Fixa diretrizes e bases para o ensino de $1^{\circ}$ e $2^{\circ}$ graus e dá outras providências. Brasília: MEC. Disponível em: https://www2.camara.leg.br/legin/fed/lei/1970-1979/lei-5692-11-agosto-1971-357752publicacaooriginal-1-pl.html. Acesso em: 8 mar. 2019.

Brasil. (1966b). Ministério da Educação. Lei de Diretrizes e Bases da Educação Nacional $n^{o}$ 9394/96, de 20 de dezembro de 1996. Estabelece as diretrizes e bases da educação nacional. Brasília: MEC. Disponível em: http://www.planalto.gov.br/ccivil_03/LEIS/L9394.htm. Acesso em: 30 mar. 2019.

Brasil. (2014). Plano Nacional de Educação. Lei no 13.005, de 14 de julho de 2014. Aprova o Plano Nacional de Educação e dá outras providências. Brasília, DF: Presidência da República. Disponível em: http://www.planalto.gov.br/ccivil_03/_Ato2011-2014/2014/Lei/L13005.htm. Acesso em: 10 out. 2019.

Di Pierro, M. C. (2005). Notas sobre a redefinição da identidade e das políticas públicas de educação de jovens e adultos no Brasil. Educação \& Sociedade, 26(92):1115-1139.

Di Pierro, M. C. (2011). Balanço e perspectivas da pesquisa sobre formação de educadores/as de jovens e adultos. In: III Seminário Nacional de Formação de Educadores de EJA. Porto Alegre. Disponível em:

http://forumeja.org.br/sites/forumeja.org.br/files/3_snf_poa.pdf. Acesso em: 20 out. 2019

Feltrin, T.; Batista, N.L. \& Becker, E.L.S. (2017). A autoformação docente como território de possibilidade: uma reflexão sobre o espaço escolar. RELACult-Revista Latino-Americana de Estudos em Cultura e Sociedade, 3(3). 
Freire, Paulo. (2000). Pedagogia da autonomia: Saberes necessários à prática educativa. 25. ed. São Paulo: Paz e Terra.

García, C.M. (1999). Formação de Professores: Para uma mudança educativa. Porto: Porto Editora.

Gil, A. C. (2017). Como elaborar projetos de pesquisa. 6. ed. São Paulo: Atlas.

Machado, M. M. (2008). Formação de professores para EJA: uma perspectiva de mudança. Revista Retratos da Escola, Brasília, 2(2-3):161-174, 2008. Disponível em: http//www.esforce.org.br. Acesso em: 22 out.

Marcelo, C. (2009). Desenvolvimento profissional docente: passado e futuro. Sísifo- Revista de Ciências da Educação, (8):7-22.

Moura, T. M.M. (2009). Formação de educadores de jovens e adultos: realidade, desafios e perspectivas atuais. Práxis Educacional, Vitória da Conquista, 5(7):45-72.

Nóvoa, A. (org.). (2013). Vidas de professores. Porto: Porto Editora.

Nóvoa. A. (1991). Para o estudo sócio-histórico da gênese e desenvolvimento da profissão docente. Teoria e Educação. Porto Alegre, (4):109-139.

Pedroso, A. P. F. \& Soares, L. J. G. (2016). Formação de Educadores na Educação de Jovens e Adultos (EJA): alinhavando contextos e tecendo possibilidades. Educação em Revista. Belo Horizonte. 32(4).

Romão, J.E.; Gadotti, M. (2007). Cenários, perspectivas e formação de educadores. Brasília: Líber Livro Editora.

Feitosa, S.C.S. (2008). Método Paulo Freire: a reinvenção de um legado. Brasília: Líber Livro Editora, 2008. 
Romão, J.E. \& Rodrigues, V. L. (2011). Paulo Freire e a educação de adultos: teorias e práticas. São Paulo: IPF; Brasília: Líber Livro Editora.

Soares, L. (2008). O educador de jovens e adultos e sua formação. Educação em Revista, Belo Horizonte, (47):83-100.

Tardif, M. (2010). Saberes docentes e formação profissional. 11. ed. - Petrópolis, RJ: Vozes.

Tozetto, S. S. (2015). Trabalho docente e suas relações com o saber. In: Trabalho docente: saberes e práticas. Curitiba: CRV.p. 21-51.

Vóvio, C.L. \& Bicas, M.S. (2006). Formação de educadores: aprendendo com a experiência. In: Construção coletiva: contribuições à educação de jovens e adultos - Ação Educativa: Brasília.

Zeichner, K. M. (1993). A Formação Reflexiva de Professores: Ideias e Práticas. Lisboa: Educa.

Zeichner, K. M. (2008). Uma análise crítica sobre a "reflexão" como conceito estruturante na formação docente. Educação e Sociedade, 29(103).

Porcentagem de contribuição de cada autor no manuscrito

Lenir Keller $-50 \%$

Elsbeth Léia Spode Becker - 50\% 